\title{
A Study on Efficient System of the Gastric Cancer Screening in the Community in Japan \\ The Relationship between the Operating Style of the Screening Program and the Population Size of Municipalities
}

\author{
Binyan Wang, Kiyomi Sakata, Yoshikazu Nakamura and Masaki Nagai
}

\begin{abstract}
In order to learn the relationship between the population size of municipalities and conducting methods of gastric cancer screening programs according to the Health and Medical Service for the Aged Act of 1982 in Japan, the programs of 2,795 municipalities having replied a questionnaire survey were analyzed. Several aspects of conducting the programs, such as whether to conduct individual screenings, how to conduct outside office hour screening, how to provide information about screening schedules, keeping and controlling systems of the results, and participation rates, depended on the population size. The difference according to the population size seemed due to differences of life style and social environment between rural and urban, and population size itself. Moreover, the population size should be considered as a confounding factor in analyzing the relationship between the gastric cancer screening program system and the participation rate. J Epidemiol, 1993; 3: 11-18.
\end{abstract}

gastric cancer screening, participation rate, population size, health care for the aged, national cross-section survey

The Health and Medical Service for the Aged Act of 1982 in Japan aims promotion of health for old people. According to the law, every municipal government performs 7 health promoting programs ; medical treatment, issue of health record booklets, health education, health consultation, health screening programs, rehabilitation, and health guidance at home. Since the enforcement of the law in 1983, health screening programs have become one of the main parts of the health promotion programs for not only the aged but also the middle aged. Five screening programs shown in Table 1, one of which is mainly for prevention of cardiovascular disease, and others of which are cancer screenings, are provided to residents wishing to take the examinations. The law requires municipal governments to undergo the programs efficiently, and to provide the opportunity for residents to use the programs with inexpensive payment ${ }^{13}$.

The law implies that appropriate distribution of these screening programs decreases mortality rates from cardiovascular disease and cancers. To date some studies with respect most to the general health examination have discussed the issues about how to conduct an appropriate examination ${ }^{2-6)}$, factors which affects participation rates $^{7-10)}$, the difference between residents participating in screenings and those not ${ }^{11-15}$, health problems according to results of the screenings ${ }^{16,17}$, cost-effectiveness of the programs ${ }^{18-20}$, and the problems about diagnosis and treatment after the screenings $^{20-23)}$. On the other hand, a few studies have analyzed the conducting system of gastric cancer screening programs ${ }^{24,25)}$.

We conducted a nationwide survey to obtain information about how municipal governments were conducting the health promoting programs in 1991. The final purpose of the survey is to establish the best enforcement for each of the programs. As the first step of the analysis for the gastric cancer screening programs, we conducted a cross-sectional study, of which observation unit was a municipality, in order to

Received December 11, 1992 ; Accepted March 22, 1993.

Department of Public Health, Jichi Medical School, 3311-1, Yakushiji, Minamikawachi, Tochigi 329-04, Japan.

Address for correspondence: Binyan Wang, Department of Public Health, Jichi Medical School, 3311-1, Yakushiji, Minamikawachi, Tochigi 329-04, Japan. 
Table 1. A list of screening programs according to the Health and Medical Service for the Aged Act of 1982, Japan.

\begin{tabular}{|c|c|c|}
\hline Health screening & Object & Examination \\
\hline General health examination & $\geq 40$ years old & $\begin{array}{l}\text { anthropometric measures, blood pressure, urinalysis, } \\
\text { electrocardiograph, optic fundus examination, } 75 \text { gram glucose toler- } \\
\text { ance test phlebotomy } \\
\text { total cholesterol, red blood cell count, hematocrit, hemoglobin concen- } \\
\text { tration, GOT*, GPT ** }\end{array}$ \\
\hline Gastric cancer schreening & $\geq 40$ years old & double-contrast barium radiography \\
\hline Lung cancer screening & $\geq 40$ years old & $\begin{array}{l}\text { chest } \mathrm{X} \text {-ray examination } \\
\text { sputum cytology for those with high risk } * * *\end{array}$ \\
\hline Cervical cancer screening & $\begin{array}{l}\geq 30 \text { years old } \\
\text { women }\end{array}$ & cervical cytology \\
\hline Breast cancer screening & $\begin{array}{l}\geq 30 \text { years old } \\
\text { women }\end{array}$ & palpation by a physician \\
\hline
\end{tabular}

* Glutamine-oxaloacetic transaminase

** Glutamic-pyruvic transaminase

*** Those whose smoking index, the daily average number of cigarettes multiplied by the duration of smoking (year), is $\geq 600$ cigarette-years, or those with a history of hemiseptum.

know how to conduct a gastric cancer screening program depending on the population size of the municipality.

\section{MATERIALS AND METHODS}

We sent questionnaires to all of the 3,268 municipal governments ( 655 cities, 2,003 towns, 587 villages, and 23 special wards in Tokyo metropolitan area) in Japan in February 1991 in order to obtain information about how the municipal governments underwent health promoting programs according to the Health and Medical Service for the Aged Act of 1982. The questionnaire included all issues about the 7 programs, and issues with respect to the gastric cancer screening program are shown in Table 2.

Since more than 90 percent of municipal governments employ public health nurses to administer health issues ${ }^{1}$, we asked that a public health nurse answered the questionnaire in such governments. For municipal governments which did not employ a public health nurse, we asked other person who took charge of the health issues to answer the questionnaire. Thus, many of the questionnaires returned to us are expected to be answered by public health nurses, who knew how to conduct the programs most at the governments.

The population size used in this study is based on the national census in $1990^{26}$. As shown in Table 2, we got population size information by decade of age for $\geq 40$ years. To analyze this as dichotomous data, every municipality was classified into 2 groups. One of the groups consisted of municipalities where the number of those aged $\geq 40$ years was less than 10,000 , and such municipalities are called small ones. The other group consisted of large municipalities where the number of those aged $\geq 40$ years was more than or equal to 10,000 . Approximately 40 percent of the population in Japan are $\geq 40$ years of age ${ }^{26)}$. Thus, a large municipality means a municipality whose total population size is about $25,000(10,000 / 0.4)$ and more.

The number of those who participated in the gastric cancer screenings between April 1991 and March 1992 divided by the population size was defined as a participation rate. The numerator and the denominator of the rate were based on the annual data list of health map published by the Ministry of Health and Welfare in $1991^{9)}$.

\section{RESULTS}

Of the 3,268 questionnaires sent out, we received 2,800 ones. Of the 2,800 municipalities participating in the study, 5 governments did not provide a gastric cancer screening program to residents despite the law. Therefore, we analyzed 2,795 municipalities, or 85.5 percent of all municipalities in Japan. The 2,795 municipalities were 1,973 (70.6 percent) small municipalities, and 822 (29.4 percent) large municipalities.

Table 3 represents the operating style of gastric cancer screening program. There are two major operating styles of the gastric cancer screenings in Japan: One is a mass screening style with special automobiles for the screening, having an X-ray apparatus inside, and the other style is an individual screening at a hospital or a clinic. Almost all of the municipalities (98.8 percent) provided the screening examinations to 
Table 2. Issues about the gastric cancer screening program in the quentionnaire, the nationwide survey in 1991, Japan.

1. Operating style.

mass screening with screening automobiles

individual screening at clinics and/or hospitals

both of them

2. Whether to entrust the program to some institutions.

If yes, all of the screening, or a part

to whom? screening agencies

public health centers

local medical associations

hospitals

others

3. Whether to conduct the screenings outside the usual office hours.

If yes, when?

4. Whether to conduct the screenings with other screening program(s) at once.

If yes, with which program(s)?

5. How to provide information of screening schedules to residents.

newsletters from the government to residents

local organization activities

house-to-house circular

letters or postcards to individuals

home visits of public health nurses

telephone calls from the government

mass communications (television, radio, newspaper)

6. Whether to exempt someone from paying a part of the cost of screening.

no

for those who are in high risk groups (e.g., $\geq 70$ y.o.)

for all participants

7. Whether to have systems for keeping individual information of screening results such that ;

individual filing system with or without a computer(s)

keeping records of those who have not participated for $\geq 3$ years

keeping information of whether to undergo detailed examinations if necessary

8. Whether to get cooperation of volunteer groups.

if yes, how? providing schedule information to residents

distributing questionnaires prior to the screening

encouraging residents to participate

aiding operation of the screening

returning results of the screening to participants

encouraging those who need detailed examinations to undergo them

9. The average number of residents and those who participated in the screening in 1991 fiscal year (from April 1991 through

March 1992 ) by 10 year age group ( $40-49$ y.o., $50-59$ y.0., $60-69$ y.o., and $\geq 70$ y.o.)

residents by mass screening with screening automobiles. In addition to the mass screening, 7.5 percent of the small municipalities and 21.3 percent of the large ones provided it by individual screening at clinics and/or hospitals. The proportion of municipalities where the screening was provided only by the individual screening style was less than 1 percent.
Many municipalities do not have the ability of conducting the screening by themselves due to lack of specialists employed, such as roentgenologists and radiographers, and lack of medical instruments for the screening due to expansiveness and inefficiency. Therefore, many of them entrust some institutions with the screening. Of the 2,795 municipalities observed, 
Table 3. The number of municipalities classified by the operating style of gastric cancer screenings, by population size of those aged $\geq 40$ years, the nationwide survey in 1991, Japan.

\begin{tabular}{lrrr}
\hline & \multicolumn{2}{c}{ Population size of $\geq 40$ years old } \\
\cline { 2 - 4 } & Overall (\%) & $<10,000(\%)$ & $\geq 10,000(\%)$ \\
\hline $\begin{array}{l}\text { The number of municipalities with } \\
\text { mass screening } \\
\text { with screening automobiles } \\
\text { individual screening at clinics } \\
\text { and/or hospitals } \\
\text { both of then } \\
\text { not classified above }\end{array}$ & $2457(87.9)$ & $1806(91.5)$ & $651(79.2)$ \\
\hline Total & $22(0.8)$ & $13(0.7)$ & $9(1.1)$ \\
\hline
\end{tabular}

2,225 ones or 79.6 percent provided the gastric cancer screening by using screening agencies, which are companies and non-profit organizations with a purpose. of providing medical examinations and screenings. Three hundred and twenty-four municipalities used local medical associations, members of which are usually physicians who manage a hospital or a clinic ; therefore, entrusting local medical associations usually means that the screenings were provided at clinics and/ or hospitals as an individual screening. The proportion of municipalities using the local medical associations was higher in the large municipality group than in the small one $(6.7$ percent and 23.3 percent, respectively). The number of municipalities using public health centers was small as 193 (6.9 percent).

In order to give residents more opportunities of participating in the screenings, many municipal governments provide a part of the screenings as an outside office hour screening, which means some of the screen- ings provided outside the usual office hours. Two thousand and ninety-eight municipal governments (75.1 percent) conducted the screening on hours other than 9 a.m. through 5 p.m. on weekdays (Table 4). The proportion of such municipalities did not differ by the population size. However, screening programs in early mornings which started before 9 a.m. were more common in the small municipalities. On the other hand, programs on Saturdays, Sundays, and/or national holidays were more familiar in the large municipalities.

In order for residents to be convenient and, accordingly, to raise participation rates, some municipalities provided more than 2 screenings at the same time. As shown in Table 5, the proportion of municipalities where the gastric cancer screening was provided with other examinations was 61.1 percent, and there was no difference of the proportion between the two municipal groups according to the population size. The

Table 4. The number of municipalities conducting the gastric cancer screenings outside the usual office hours, by population size of those aged $\geq 40$ years, the nationwide survey in 1991, Japan.

\begin{tabular}{lccc}
\hline & \multicolumn{2}{c}{ Population size of $\geq 40$ years old } \\
\cline { 2 - 4 } & Overall (\%) & $<10,000(\%)$ & $\geq 10,000(\%)$ \\
\hline $\begin{array}{l}\text { The number of municipalities conducting } \\
\text { outside office hour screening }\end{array}$ & $2098(75.1)$ & $1489(75.5)$ & $609(74.1)$ \\
\hline in early mornings & & & $382(62.7)$ \\
on Sundays and/or national holidays ${ }^{+}$ & $1529(72.8)$ & $1167(78.3)$ & $241(39.6)$ \\
on Saturdays ${ }^{+}$ & $598(28.5)$ & $357(24.0)$ & $203(33.3)$ \\
others & $458(21.8)$ & $255(17.1)$ & $88(14.4)$ \\
\hline Total & $274(13.1)$ & $186(12.5)$ & $822(100)$ \\
\hline
\end{tabular}

+ Because some municipalities conducted more than 2 kinds of outside Office hour screenings, the sum of these 4 categories exceeded the total number of municipalities conducting such screenings. 
Table 5. The number of municipalities conducting the gastric cancer screening program with other screening(s) at once, by population size of those aged $\geq 40$ years, the nationwide survey in 1991, Japan.

\begin{tabular}{|c|c|c|c|}
\hline & \multicolumn{3}{|c|}{ Population size of $\geq 40$ years old } \\
\hline & Overall (\%) & $<10,000(\%)$ & $\geq 10,000(\%)$ \\
\hline $\begin{array}{l}\text { The number of municipalities conducting } \\
\text { with other screening(s) at once }\end{array}$ & $1709(61.1)$ & $1199(60.8)$ & $510(62.0)$ \\
\hline with general health examination ${ }^{+}$ & $807(74.3)$ & $588(75.9)$ & $219(70.2)$ \\
\hline with lung cancer screening ${ }^{+}$ & $359(33.1)$ & $241(31.1)$ & $118(37.8)$ \\
\hline with cervical cancer screening ${ }^{+}$ & $307(28.3)$ & $198(25.6)$ & $109(34.9)$ \\
\hline with breast cancer screening ${ }^{+}$ & $191(17.6)$ & $123(15.9)$ & $68(21.8)$ \\
\hline Total & $2795(100)$ & $1973(100)$ & $822(100)$ \\
\hline
\end{tabular}

general health examination was the most common screening which was conducted with the gastric cancer screening, and the breast cancer screening was the least common.

How to provide information about screening programs, such as schedules, fees, and how to take examinations, is important for municipal governments to raise the participation rates, and various methods were used. As shown in Table 6, using newsletters issued by municipal governments was the most common media through which the information was provided to residents, and the proportion of municipalities using this method was higher in the large municipality group than in the small one. Using a personal letter or postcard to an individual resident was the second most common method, which was more popular in the large municipality group. Using house-to-house circular was more familiar in the large municipalities as well.

Table 6. The number of municipalities using several methods to provide information about gastric cancer screening program to residents, by population size of those aged $\geq 40$ years, the nationwide survey in 1991 , Japan.

\begin{tabular}{lccc}
\hline & \multicolumn{2}{c}{ Population size of $\geq 40$ years old } \\
\cline { 2 - 4 } & Overall (\%) & $<10.000(\%)$ & $\geq 10,000(\%)$ \\
\hline The number of municipalities using ; & & $1609(81.6)$ & $755(91.8)$ \\
newsletter* & $2364(84.6)$ & $1297(65.7)$ & $442(53.8)$ \\
local organization activity* & $1739(62.2)$ & $919(46.6)$ & $437(53.2)$ \\
house-to-house circular* & $1356(48.5)$ & $1204(61.0)$ & $541(65.8)$ \\
personal letter or postcard* & $1745(62.4)$ & $376(19.1)$ & $124(15.1)$ \\
home visit of public health nurses* & $500(17.9)$ & $221(11.2)$ & $100(12.2)$ \\
telephone* & $321(11.5)$ & $47(2.3)$ & $27(3.3)$ \\
mass communications* & $74(2.6)$ & $1375(69.7)$ & $469(57.1)$ \\
\hline $\begin{array}{l}\text { direct personal contact*** } \\
\text { indirect personal contact**** }\end{array}$ & $1844(66.0)$ & $1204(61.0)$ & $541(65.8)$ \\
impersonal contact**** & $1745(62.4)$ & $1766(89.5)$ & $783(95.3)$ \\
\hline Total & $2549(91.2)$ & $1973(100)$ & $822(100)$ \\
\hline
\end{tabular}


Table 7. The number of municipalities with special information about results of the gastric cancer screening program, by population size of those aged $\geq 40$ years, the nationwide survey in 1991, Japan.

\begin{tabular}{cccc}
\hline & \multicolumn{2}{c}{ Population size of $\geq 40$ years old } \\
\cline { 2 - 4 } & Overall (\%) & $<10,000(\%)$ & $\geq 10,000(\%)$ \\
\hline $\begin{array}{c}\text { The number of municipalities with } \\
\text { individual filing system } \\
\text { with/without a computer(s) } \\
\text { with a computer(s) }\end{array}$ & $1507(53.9)$ & $1118(56.7)$ & $389(47.3)$ \\
& $776(27.8)$ & $550(27.9)$ & $226(27.5)$ \\
\hline $\begin{array}{l}\text { keeping records of those who } \\
\text { have not participated } \\
\text { for } \geq 3 \text { years }\end{array}$ & $381(13.6)$ & $326(16.5)$ & $55(6.7)$ \\
\hline $\begin{array}{l}\text { keeping information of } \\
\text { participating in detailed } \\
\text { examinations }\end{array}$ & & & $651(79.2)$ \\
\hline Total & $2298(82.2)$ & $1647(83.5)$ & $822(100)$ \\
\hline
\end{tabular}

On the other hand, using local organization activities, which means that members of the local organizations make a house-to-house visit to provide information, and public health nurses' home visits were more common in the small municipality group. These methods were classified as three categories: direct personal contacts comprised of local organization activities, home visits of public health nurses, and telephone calls ; indirect personal contacts with letters and postcards; and impersonal contacts comprised of newsletters, house-to-house circulars, and mass communications. The direct personal contact was the most personal contact, and the impersonal contact was the least one. As shown in Table 6, the direct personal contact was more common in the small municipality group, and the impersonal contact were more common in the large municipalities.

As shown in Table 2, there are three policies with respect to exemption from paying part of the fees of the screening; no exemption, for those who are in high risk groups, such as old age groups, and for all participants. One thousand and six municipalities $(36.0$ percent) had the no exemption policy, whereas 1,347 ones ( 48.2 percent) had the partial exemption policy and 442 ones (15.8 percent) did not collect a charge. The proportions did not differ by the population size of the municipalities.

Overall, 1,507 municipalities (53.9 percent) had individual filing systems to keep and control information of the screening results at the governmental office, and the proportion of such municipalities was higher in the small municipalities than in large ones (Table 7). However, the proportion of municipalities which used computers for the filing system did not differ between
Table 8. Participation rates (percent) for the gastric cancer screening program, by age and population size of those aged $\geq 40$ years, the nationwide survey in 1991, Japan.

\begin{tabular}{cccc}
\hline \multirow{2}{*}{ Age (year) } & \multicolumn{3}{c}{ Population size of $\geq 40$ years old } \\
\cline { 2 - 4 } & Overall (\%) & $<10,000(\%)$ & $\geq 1,000(\%)$ \\
\hline $40-49$ & 12.3 & 14.6 & 6.6 \\
$50-59$ & 14.4 & 17.1 & 8.1 \\
$60-69$ & 21.8 & 25.6 & 12.8 \\
$\geq 70$ & 8.3 & 9.8 & 4.3 \\
\hline Overall & 14.3 & 16.9 & 7.9 \\
\hline
\end{tabular}

the population size. That means individual filing system without computers was more common in small municipality group. In addition, small municipalities were more likely to keep records of those who had not participated in the screenings for $\geq 3$ years than large ones. Approximately 15 percent of those participating in the gastric cancer screenings are required to take detailed or secondary examinations because of the results of the screening ${ }^{19)}$. However, all of them do not take the examinations, which are not included in the gastric cancer screening program of the law. Many municipalities attempt to obtain information whether each person required the detailed or secondary examinations took them or not, and 82.2 percent of the municipalities kept this information. The proportion of such municipalities was higher in the small municipality group than in the large one (Table 7).

There are many local voluntary organizations, such as organizations for old persons, organizations for 
women, and organizations for farmers, and 2,188 municipalities ( 78.3 percent) got their cooperation to undergo the gastric cancer screening programs. The proportion of municipalities getting the cooperation was higher in the small municipalities than in the large ones ( 81.4 percent and 70.8 percent, respectively). Details of the cooperation were; providing schedule information to residents (83.8 percent of municipalities), aiding operation of the screening ( 59.0 percent), distributing questionnaires prior to the screening (45.5 percent), encouraging residents to participate (45.2 percent), and returning results of the screening to participants ( 25.6 percent). The proportion of each of the details was higher in the small municipality group than in the large one, especially for distributing questionnaires, encouraging to participate, and returning results.

Participation rates for the gastric cancer screening program by age and population size of municipalities are shown in Table 8 . The rate for overall age group was 14.3 percent. The rate was highest in those who were 60's of age, and lowest in those who were $\geq 70$ years of age. The rates in small municipalities were approximately twice as high as those in large municipalities in all age groups.

\section{DISCUSSION}

This study shows that several aspects of conducting gastric cancer screening programs according to the Health and Medical Service for the Aged Act of 1982 depended on the population size of municipalities. In addition, how municipal governments conducted the screening programs and how many residents participated in the screenings are shown in detail.

The results we obtained can be explained by differences of life styles between town and country. For example, screenings on early mornings were less common in large municipalities because many employees lives in town and they are usually busy before going to working place in the morning. Thus, screenings on weekends and holidays were preferred in town. Human relations are closer in country, so the direct personal contact on providing information of the screening schedules and cooperation of voluntary organizations were more common in small municipalities.

Another issue that explains the different results between town and country is the social environment. As shown in Table 3, 22.4 percent of the large municipalities used clinics and/or hospitals for individual screening and this percentage was more than twice as high as that for small municipalities. Because medical institutions are likely to exist in town, and the trans- port infrastructure develops more in town, large municipalities can use individual screening at clinics and/or hospitals. In other words, some small municipalities had no option for the screening style except mass screening with screening automobiles because of their poor environment about medical institutions and transportation systems.

The other issue about the difference observed between small municipalities and large ones is the population size itself. Though the proportion of the small municipalities using individual filing system with computers was similar to that of the large municipalities, the proportion of the small municipalities with individual filing system with/without computers was higher than that of the large municipalities (Table 7). That means that the small municipalities were likely to use individual filing system even though computers were not available, and that the filing system without computers were possible because of the small population size. A similar situation might affect the results of keeping records of those who had not participated for $\geq 3$ years (Table 7).

The overall participation rate, 14.3 percent, was higher than the average participation rate of the whole country in 19909.10). Even though the participation rates have increased year by year ${ }^{9,10,27)}$, this might be due to selection bias, e.g., municipalities with low participation rate did not send back the questionnaire. Nevertheless, the results of participation rates obtained in detail, which were that the rate was higher in small municipalities than in large municipalities, and that the rate increased according to aging except for those who were $\geq 70$ years old, were similar to those in previous studies $^{8}$. Therefore, the results of the current study suggest that the key issues to increase the participation rate in the whole country are the rate in town and the rate of old persons who are $\geq 70$ years old, whose mortality rate from gastric cancer is high.

There are several issues for municipal governments to raise the participation rate for the gastric cancer screening program: how and when to conduct the screenings, how to encourage residents to participate, and how to keep results of the screening. To learn the best way for high participation rate, we are going to analyze the current data by classifying municipalities as those with high rate and those with low rate. The current study shows that in such analyses, we must pay attention to the population size as a confounding factor.

\section{ACKNOWLEDGEMENTS}

The authors are grateful specially to Prof. Hiroshi YANAGAWA, Dr. Toshiyuki OJIMA and the staff of the Dept. of 
Public Health in Jichi Medical School for their support and interest ; and thank 3,268 municipalities for their cooperation of the data collection in this work.

\section{REFERENCES}

1. Ministry of Health \& Welfare: The Health \& Medical Service for the Aged, Act and its related Regulations, edition in 1990; 479, 483 (in Japanese).

2. Adachi Y, Matsumoto K, Konishi E. Referral Compliance Improved by a Letter of Introduction to a Special Physician Following Mass Screening. Jpn J Pub Hlth, $1989 ; 7: 413-420$.

3. Mine M, Nakamura T. Study for Quantitation Assessment of Health Screening Effect on Life Span. Jpn J Pub Hlth, 1988; $7: 327-334$.

4. Nakamura Y, Sakata K, Hara H. A proposal For Evaluation Charts on the Health Services for the Aged by Municipalities. Jpn J Pub Hlth, 1990; 2 : 73-82.

5. Ohara $\mathbf{H}$, Ishikawa $\mathrm{Y}$, Tagami T. A Study on the Changes of Health Activities and Functions of Health Center in a Community After the Enforcement of the Health Service Law for Elderly. Jpn J Pub Hlth, 1987; 2: 73-80.

6. Yamaguchi N, Okubo T, Yamamura J. A Prospective Study of Access to Medical Service Following a Community-Based Screeening Program. Jpn J Pub Hlth, $1990 ; 4: 281-288$.

7. Takeda S, Aoyagi I, Amano M. An Analysis of Participation Rates For Health and Cancer Screenings in Wakabashi Ward of Sendai. Jpn J Pub Hlth, 1991 ; 6: 425-430.

8. Sugawara N, Fukao A, Takahashi H. An Study on the Community-Based Health Examination Related to the Gastric Cancer Screening. KOUSEI NO SIHYOU,1990; 37(1): 23-28 (in Japanese).

9. Ministry of Health \& Welfare. The Annual Data List of Health Map of The Municipalities in Japan, 1990 \& 1991 (in Japanese).

10. Statistics \& Information Department, Ministry of Health \& Welfare. Report of Health Service for the Aged, 1990 \& 1991 (in Japanese).

11. Ozasa K. Characteristics of Participants in Multiphasic Health Examination I. Jpn J Hyg, 1988 ; 5 : 995-999.

12. Ozasa K. Characteristics of Participants in Multiphasic Health Examination II. Jpn J Hyg, 1988; 5: 1004-1011.

13. Kato I, Tominaga S, Naruhashi H. Characteristics of Participants of Gastric Cancer Screening Test, Part I. Jpn J Pub Hith, 1986; 12: 735.

14. Kato I, Tominaga S, Naruhashi H. Characteristics of Participants of Uterine Cancer Screening Test, Part II.
Jpn J Pub Hlth, 1987; 12: 749.

15. Mori S, Nakayama $\mathbf{H}$, Okamoto $\mathbf{N}$. Participation of Regional Inhabi-tants in Cancer Screening. Jpn J Pub Hlth, $1990 ; 8: 559-568$.

16. Aoyama M, Omori $M$, Makino S. The Relationship Between the Finding of Left Ventricular High Voltage and ST, T, Changes on ECG and Life Styles of the Health Examination Participants. Jpn J Pub Hlth, 1987; 6: 278-286.

17. Jinguu $S$, Suemitu $T$, Kazato $H$. Health Examination for the Citizen Aged 40 Years in Fukuoka City: A View on the Relative Problems in Health Care. Jpn J Pub Hlth, $1986 ; 7: 349-355$ (in Japanese).

18. Iinuma $\mathrm{T}$, Tateno $\mathrm{Y}$. Cost-Effectiveness of the Mass Screening for Stomach Cancer. J of Gastroenterological Mass Survey, 1988; 6: 94-100.

19. Ministry of Health \& Welfare. The Report of the Fifth National Survey Related to Malignant Neoplasm, 1989 (in Japanese).

20. Hisamichi S, et al. A series of Evaluations Related to the Effect of Gastric laneer Screening, 1983 (in Japanese).

21. Hamashima C, Masuda Y, Okamura T. Credibility of the Inconclusive Findings on the Indirect $X$-ray in Gastric Mass Survey: From a Point of View of Medical Decision Making. J of Gastroenterological Mass Survey, 1990; 3 : 33-4l.

22. Nishizawa M, Nomoto K, Hosoi D. Problems in Gastric Cancer Mass Screening and Their Improvement (Part II) : Various Methods of Mass Screening and Evaluation of Their Effeciency. J of Gastroenterolog-ical Mass Survey, 1981; Vol 53: $42-46$ (in Japanese).

23. Kusaba I. The State of the Stomach Cancer Operation and the Mothods of Gastric Mass Screening: On the View of Duration of Illness and Treatment History of Gastric Ulcer. J of Gastroenterological Mass Survey, 1983; 12 : 26-36 (in Japanese).

24. Sakata K. A Study on the Health Examination Services Under the Health Service Law for the Aged-An Analysis of the Differences Among Local Governments By Population Size. Jpn J Hyg, 1988; 6: 1056-1063.

25. Fujisaku T, Sekita Y. Evaluation to the Effect of Gastric Cancer Examination: An Approach Model of Efficient Program of Gastric Cancer Screening. J of Gastroenterological Mass Survey, 1984; $3: 85-93$ (in Japanese).

26. Statistics Bureau, Management \& Coordination Agency : 1990 Population Census of Japan (in Japanese).

27. Ministry of Health \& Welfare. New Mannual for Health Care Undertaking: An Outline of the Second Five-year Planning, 1987 (in Japanese). 